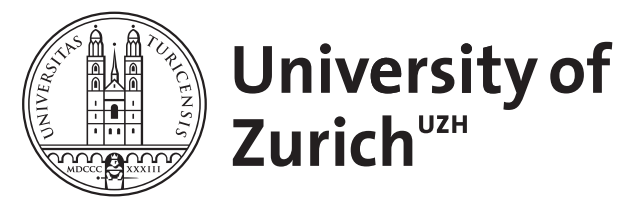

\title{
Effects of methylphenidate: the cellular point of view
}

\author{
Bartl, J ; Link, P ; Schlosser, C ; Gerlach, M ; Schmitt, A ; Walitza, S ; Riederer, P ; Grünblatt, E
}

\begin{abstract}
The psychostimulant methylphenidate (MPH) is the first choice of treatment in attention-deficit hyperactivity disorder and is based mainly on inhibition of dopamine transporter (DAT). Nonetheless, the complete cellular effects of MPH are still unknown. We attempted to determine whether MPH influences neurotransmitter levels, synaptic gene expression, and cell proliferation in a dose-dependent manner in rat pheochromocytoma cells (PC12) lacking DAT. PC12 were treated in a dose-dependent manner with MPH. Gene expression level of synaptotagmin (Syt) 1 and 4, syntaxin 1a (Stx1a), and synaptic vesicle glycoprotein 2C (SV2C) was measured using quantitative real-time RT-PCR. Different Neurotransmitter release was measured using high-performance liquid chromatography (HPLC). Differences in cell proliferation were evaluated via BrdU incorporation. Treatment with low-dose MPH (1-100 $\mathrm{nM}$ ) altered intra-/extracellular neurotransmitter levels, down-regulated all investigated genes as well as enhanced cell proliferation significantly. These data point to diverse effects of MPH on cell metabolism independent of inhibiting DAT.
\end{abstract}

DOI: https://doi.org/10.1007/s12402-010-0039-6

Posted at the Zurich Open Repository and Archive, University of Zurich ZORA URL: https://doi.org/10.5167/uzh-43272

Journal Article

Published Version

Originally published at:

Bartl, J; Link, P; Schlosser, C; Gerlach, M; Schmitt, A; Walitza, S; Riederer, P; Grünblatt, E (2010). Effects of methylphenidate: the cellular point of view. ADHD Attention Deficit and Hyperactivity Disorders, 2(4):225-232.

DOI: https://doi.org/10.1007/s12402-010-0039-6 


\title{
Effects of methylphenidate: the cellular point of view
}

\author{
Jasmin Bartl • Pille Link • Corinna Schlosser • \\ Manfred Gerlach • Angelika Schmitt • \\ Susanne Walitza $\cdot$ Peter Riederer · Edna Grünblatt
}

Received: 23 May 2010/Accepted: 12 October 2010/Published online: 10 November 2010

(C) Springer-Verlag 2010

\begin{abstract}
The psychostimulant methylphenidate (MPH) is the first choice of treatment in attention-deficit hyperactivity disorder and is based mainly on inhibition of dopamine transporter (DAT). Nonetheless, the complete cellular effects of MPH are still unknown. We attempted to determine whether MPH influences neurotransmitter levels, synaptic gene expression, and cell proliferation in a dosedependent manner in rat pheochromocytoma cells (PC12) lacking DAT. PC12 were treated in a dose-dependent manner with MPH. Gene expression level of synaptotagmin (Syt) 1 and 4, syntaxin 1a (Stx1a), and synaptic vesicle glycoprotein $2 \mathrm{C}$ (SV2C) was measured using quantitative
\end{abstract}

Electronic supplementary material The online version of this article (doi:10.1007/s12402-010-0039-6) contains supplementary material, which is available to authorized users.

J. Bartl · P. Link · C. Schlosser · P. Riederer · E. Grünblatt ( $\square)$ Clinical Neurochemistry Laboratory, Clinic and Policlinic for Psychiatry, Psychosomatic and Psychotherapy,

University of Würzburg, Füchsleinstr. 15,

97080 Würzburg, Germany

e-mail: edna.gruenblatt@kjpdzh.ch

M. Gerlach

Department of Child and Adolescent

Psychiatry and Psychotherapy,

University of Würzburg, 97080 Würzburg, Germany

\section{A. Schmitt}

Molecular and Clinical Psychobiology,

Clinic and Policlinic for Psychiatry,

Psychosomatic and Psychotherapy,

University of Würzburg, 97080 Würzburg, Germany

S. Walitza $\cdot$ E. Grünblatt

Department of Child and Adolescent Psychiatry,

University of Zurich, Neumuensterallee 9,

8032 Zurich, Switzerland real-time RT-PCR. Different Neurotransmitter release was measured using high-performance liquid chromatography (HPLC). Differences in cell proliferation were evaluated via BrdU incorporation. Treatment with low-dose MPH (1-100 nM) altered intra-/extracellular neurotransmitter levels, down-regulated all investigated genes as well as enhanced cell proliferation significantly. These data point to diverse effects of MPH on cell metabolism independent of inhibiting DAT.

Keywords Methylphenidate - PC12 cells . Synaptic Proteins - Norepinephrine Transporter . Neurotransmitter release $\cdot$ Cell proliferation

\section{Introduction}

Attention-deficit/hyperactivity disorder (ADHD) is the most frequent psychiatric disorder in children and adolescents, with up to 6-12\% affected worldwide (Biederman and Faraone 2005). ADHD is characterized by the constitutive development of inappropriate levels of inattention, hyperactivity, and/or impulsiveness. The cause and pathophysiology of ADHD are still unknown, but there is immense evidence that ADHD has multiple aetiologies (e.g. genetic, environmental, neurobiological, and neurochemical) in which catecholamine dysfunction, including afferent dopaminergic and noradrenergic neurotransmission, has an important underlying feature (Wilens 2008). The noradrenergic system modulates higher cortical functions, such as attention, alertness, vigilance, and executive functions, which are impaired in a variety of psychiatric disorders such as ADHD (Hahn, Steele et al. 2009). The norepinephrine transporter (NET), an important component of the noradrenergic system, involves in 
the reuptake of norepinephrine (NE) into the presynaptic terminals. A recent report implicates the involvement of NET in ADHD (Kim, Hahn et al. 2006), in which they identified a functional polymorphism in the human NET gene that decreases promoter function and was significantly associated with ADHD. Considering the neurobiology of ADHD, it is reasonable to hypothesize that medications that increase dopamine (DA) or NE availability and/or decrease their breakdown should improve ADHD symptoms.

Stimulants are part of the standard treatment for ADHD. Methylphenidate (MPH), a central nervous system stimulant with an approximately 70-year history of use, is the most frequently prescribed drug for the symptomatic treatment of ADHD and has consistently shown efficacy. However, the mechanism by which low doses of MPH reduce the activity and increase the attention is still unknown. Functionally, MPH is a high-affinity inhibitor of dopamine transporter (DAT) and NET, blocking the inward transport of DA and NE (Gatley, Pan et al. 1996; Han and $\mathrm{Gu}$ 2006). A recent study showed the effect of MPH on vesicular monoamine transporter 2 (VMAT-2) in rats after in vivo administration. The results of the study indicated that a single dose of MPH redistributes VMAT-2 and associated vesicles within nerve terminals from the synaptosomal membranes to the cytoplasm. In addition, MPH administration leads to increased DA in the vesicle fraction (Volz, Farnsworth et al. 2008). Considering these findings and the knowledge that MPH function is not solely the inhibition of DAT, we decided to investigate the effects of in vitro MPH treatment in neuronal cell line devoid of DAT expression, on neurotransmitter levels, gene expression profile of synaptic proteins, and cell proliferation, in order to elucidate the additional molecular mechanism of MPH. The cell culture model chosen for this investigation was the rat PC12 cell line, derived from rat pheochromocytoma, a tumor arising from the chromaffin cells of the adrenal medulla. PC12 cells are a common model for studying neurobiochemical and neurobiological events (Jaeger 1985). These cells have been widely used as an in vitro experimental model to study the effects of various neuroactive compounds and contain many membrane-bound and cytosolic neuron-associated macromolecules (Shafer and Atchison 1991). Previously it was reported that proliferating PC12 cells highly express NET and in very low levels express DAT, while in differentiated PC12 cells DAT expression was detected (Kadota, Yamaai et al. 1996). We used proliferating PC12 cells (originated form Israel, old generation ATCC) in which we could detect high expression of NET but no DAT expression at all whatsoever (see Suppl. Figure S1 and S2), which makes this model an ideal model to study MPH effects not associated with DAT inhibition.

\section{Materials and methods}

\section{Cell culture}

PC12 cells used in this study were generous gift from the laboratory of Dr. Silvia Mandel, Technion Faculty of Medicine, Haifa, Israel (old generation originating from ATCC) and grown in buffered Dulbecco's modified Eagle medium (DMEM) (Pan Biotech $\mathrm{GmbH}$, Aidenbach, Germany) supplemented with $10 \%$ fetal bovine serum, $5 \%$ horse serum, and $0.3 \%$ gentamycin $(50 \mathrm{mg} / \mathrm{ml})$ (Invitrogen, Karlsruhe, Germany) in a humidified incubator $\left(5 \% \mathrm{CO}_{2}\right)$ at $37^{\circ} \mathrm{C}$.

\section{MPH treatment}

For high-performance liquid chromatography (HPLC), quantitative real-time polymerase chain reaction (QRT$\mathrm{PCR})$, and BrdU incorporation experiments, PC12 cells were treated with varying concentrations of MPH (SigmaAldrich, Schnellendorf, Germany) (1, 10, $100 \mathrm{nM}, 1,10$, $100 \mu \mathrm{M})$, or purified water as a control, by adding it to the culture medium.

For BrdU incorporation analysis, the MPH incubation was stopped after $24 \mathrm{~h}$. For QRT-PCR and HPLC, the reaction was stopped after $48 \mathrm{~h}$. MPH was protected from light for all treatments, and the dilutions were always freshly prepared. The cells were incubated with MPH under dark conditions in order to reduce MPH degradation. Handling MPH in the dark delays the drug's degradation reaction (Suppl. Figure S3).

\section{Catecholamine determination via HPLC}

PC12 cells were plated at a density of $4 \times 10^{5}$ cells $/ \mathrm{mL}$ into a 24-well plate (Sarstedt, Nuembrecht, germany) and treated with MPH as described above. Reverse-phase HPLC was used to measure the intracellular and extracellular concentrations of DA, its metabolites 3,4-dihydroxyphenylacetic acid (DOPAC) and homovanillic acid (HVA); $\mathrm{NE}$, its metabolite 3-methoxy-4-hydroxy-phenylglycol (MHPG); and serotonin (5-HT) and its metabolite 5-hydroxyindole acetic acid (5-HIAA). Cells were sonicated in ice-cold $90 \%(\mathrm{v} / \mathrm{v}) 0.1 \mathrm{mM} \mathrm{Na} 2 \mathrm{PO}_{4}(\mathrm{pH} \mathrm{4.0)}$ ) and $10 \%(\mathrm{v} / \mathrm{v})$ methanol containing $0.1 \mathrm{mM}$ EDTA (Sigma, Munich, Germany), $0.65 \mathrm{mM}$ octanesulfonic acid, and 0.5 $\mathrm{mM}$ triethylamine. Homogenates were centrifuged at $19,000 \mathrm{~g}$ for $20 \mathrm{~min}$ at $4^{\circ} \mathrm{C}$ and the supernatants were used for the measurements. For the analysis of neurotransmitters and metabolites, the supernatants from cell homogenates or medium from the cell culture suspensions were measured using HPLC as described by Riederer and Reynolds (1981). The concentrations of DA, DOPAC, HVA, NE, 
MHPG, 5-HT, and 5-HIAA in the cell culture medium were measured before the experiment and subtracted from the concentration measured at the end of the experiment to obtain the amount of neurotransmitter released. Probes were quantified using an external standard that contained all detected neurotransmitters and metabolites at different concentrations ( $80 \mathrm{ng} / \mathrm{mL}, 40 \mathrm{ng} / \mathrm{mL}$, and $20 \mathrm{ng} / \mathrm{mL}$ ).

\section{Immunocytochemistry}

PC12 cells were plated at a density of $1.5 \times 10^{5}$ cells $/ \mathrm{mL}$ in poly-D-lysine/laminin-coated culture slides (BD Biosciences, Heidelberg, Germany) and differentiated with $50 \mathrm{ng} / \mathrm{mL}$ human NGF- $\beta$ (Sigma, Munich, Germany) for 7 days (this procedure was conducted only for the immunocytochemical analysis). After incubation, the cells were washed in phosphate-buffered saline (PBS) and fixed with ice-cold acetone/ methanol (1:1) for $10 \mathrm{~min}$. After three PBS washes, the cells were incubated with a blocking solution containing $5 \%$ goat serum and $0.3 \%$ Triton X-100 in PBS for $2 \mathrm{~h}$ at room temperature to block non-specific binding. The cells were then incubated overnight in antiserum diluted in blocking solution 1:50 for synaptotagmin 1 (syt1) (Abcam, Cambridge, MA, USA), synaptotagmin 4 (syt4) (Santa Cruz Biotechnology, Heidelberg, Germany), and syntaxin 1A (stx1a) (Lifespan Biosciences, Seattle, WA) and 1:100 for synaptophysin (syp) (Sigma). Cells were subsequently incubated with cyanine 2and 3 (Cy3 and Cy2)-labeled secondary antibodies diluted $(1: 200)$ in blocking solution for $2 \mathrm{~h}$ in the dark at room temperature to visualize the bound primary antibody. After washing, cells were mounted with Vectashield (Vector Laboratories, Burlingame, CA, USA). Immunofluorescence was observed using a Leica TCS SP2 confocal microscope.

\section{RNA extraction and QRT-PCR}

PC12 cells were plated at a density of $4 \times 10^{5}$ cells $/ \mathrm{mL}$ into a 24-well plate (Sarstedt, Nuembrecht, germany) and treated with MPH as described above. Total RNA was extracted from PC12 cells using the RNeasy Plus MiniKit (Qiagen, Hilden, Germany) according to the manufacturer's instructions. Total RNA (500 ng) was reverse transcribed using the iScript cDNA Synthesis Kit (Bio-Rad Laboratories, Munich, Germany). QRT-PCR was performed using an iCycler $\mathrm{iQ}^{\mathrm{TM}}$ Real Time PCR Detection System (Bio-Rad) and the SYBRGreen detection method. The QRT-PCR reaction was optimized according to the manufacturer's instructions. QuantiTech Primer assays for syt1 (catalog no. QT01573 019), syt4 (QT00195664), stxla (QT01083229), NET (QT00184604), $\beta$-actin (Actb; QT00193473), aminolevulinic acid synthase 1 (Alas1; QT00436310), and ribosomal protein L13A (Rpl13a; QT00425873) were purchased from
Qiagen. Actb, Alasl, and Rpl13a were used for normalization according to GeNorm (Vandesompele et al. 2002).

The amplified transcripts were quantified using the comparative threshold cycle $(\mathrm{Ct})$ analyzed using the BioRad iCycler iQ program.

\section{BrdU incorporation}

PC12 cells were plated at a density of $1 \times 10^{5}$ cells $/ \mathrm{mL}$ in poly-D-lysine/laminin-coated culture slides (BD Biosciences) and incubated at $37^{\circ} \mathrm{C}$ overnight in a humidified atmosphere of $5 \% \mathrm{CO}_{2}$. The next day, settled cells were treated with different doses of MPH and incubated for $24 \mathrm{~h}$ under the same conditions.

To identify the proliferating cells and cells in S-phase of the cell cycle under proliferating conditions, cells were exposed to $10 \mu \mathrm{M} \mathrm{BrdU}$ (Roche) for $4 \mathrm{~h}$ at $37^{\circ} \mathrm{C}$ for incorporation into newly synthesized DNA. Cells were then fixed with $4 \%$ paraformaldehyde for $20 \mathrm{~min}$. Three PBS washes were performed prior to DNA denaturation with $2 \mathrm{M} \mathrm{HCl}$ for $45 \mathrm{~min}$ at room temperature. Neutralization was carried out by incubating cells in $0.15 \mathrm{M}$ sodium borate buffer for $10 \mathrm{~min}$ at room temperature. The cells were then washed three times with PBS. The cells were incubated with blocking solution for $2.5 \mathrm{~h}$ at room temperature to block non-specific binding. The cells were then incubated with primary mouse anti-BrdU $(1: 100)$ overnight at $4^{\circ} \mathrm{C}$. Antibody detection was performed as described in the "Immunocytochemistry" part. Sixteen independent experiments were conducted, and BrdU incorporation was done in duplicate with four evaluated pictures for each dose $(n=16)$. The BrdU-positive cells were calculated as percentage to all stained cells.

\section{Statistical analysis}

Statistical analyses of the HPLC, QRT-PCR, and proliferation data were performed using StatView for Windows (SAS Institute Inc., version 5). Statistical tests included analysis of variance (ANOVA) with post hoc Scheffe Test. Significance was set as $P<0.05$. For a better comparison of the data, we normalized the results and converted the data into percentages. The control group was set as $100 \%$.

\section{Results}

Using Western blot and real-time PCR for the detection of DAT and NET in PC12, we could show that the PC12 obtained from Israel presented no DAT expression but a high NET expression (Suppl. Figure S1 and S2). 
Neurotransmitter alteration in MPH-treated PC12 cells

\section{Alteration of NE and MHPG levels}

The intracellular NE concentration was 3-19 ng/mL. Higher NE concentrations were measured in the cell medium (extracellular) $(50-120 \mathrm{ng} / \mathrm{mL})$. The extracellular MHPG concentration was below the level of detection $(<2.2 \mathrm{ng} / \mathrm{mL})$.

The intracellular NE concentration was significantly reduced by MPH treatment compared to control at doses of $10 \mathrm{nM}-100 \mu \mathrm{M}(-30 \%$ for $10 \mathrm{nM} ;-80 \%$ for $100 \mathrm{nM}, 1$, and $10 \mu \mathrm{M}$; and $-88 \%$ for $100 \mu \mathrm{M} ; P<0.001$; Fig. 1a). On the other hand, intracellular MHPG levels increased at low doses of MPH (1-100 nM; Fig. 1a). The turnover rate of NE seems to increase as a consequence of MPH treatment (Suppl. Table S1). The extracellular concentration of NE significantly increased at MPH doses of $1-100 \mathrm{nM}$ $(+70-80 \%$ compared to control, $P<0.01)$. Since the extracellular MHPG levels were below the limits of HPLC sensitivity, no alterations could be observed in the extracellular samples.

\section{Alterations of DA, DOPAC, and HVA levels}

The intracellular DA concentration was $30-120 \mathrm{ng} / \mathrm{mL}$, whereas the extracellular concentration was $9-160 \mathrm{ng} / \mathrm{mL}$. Intracellular DOPAC concentrations were $3-5 \mathrm{ng} / \mathrm{mL}$, and the extracellular concentration was $26-120 \mathrm{ng} / \mathrm{mL}$. The intracellular HVA concentration was below the level of detection, whereas the extracellular concentration was $400-1,300 \mathrm{ng} / \mathrm{mL}$.

The intracellular DA concentration increased significantly with MPH doses of $1-100 \mathrm{nM}(1 \mathrm{nM}+35 \%, 10 \mathrm{nM}$ $+37 \%, 100 \mathrm{nM}+58 \%$ compared to control; $P<0.02$; Fig. 1b) and decreased after treatment with $10 \mu \mathrm{M}$ or $100 \mu \mathrm{M} \mathrm{MPH}$, but the decrease was only significant for $100 \mu \mathrm{M}$ (-52\% compared to control, $P<0.0001$; Fig. 1B). No significant effect on intracellular DOPAC and HVA levels was observed after MPH treatment (Fig. 1b). Similarly, the turnover of DA into DOPAC was not significantly altered as a consequence of MPH treatment (Suppl. Table S1).

The extracellular concentration of DA was significantly decreased after treatment with 1-100 nM MPH ( -90 to $-95 \%$ compared to control, $P<0.0001$ ), whereas no alteration in the extracellular DA concentration was observed at high doses (Fig. 1b). A significant decrease in the extracellular DOPAC concentration ( -70 to $-75 \%$ compared to control, $P<0.0005)$ was observed only at high MPH doses (1-100 $\mu \mathrm{M})$. After treatment with low doses of MPH, the extracellular HVA concentration significantly increased $(1 \mathrm{nM}$ $+180 \%, P<0.0001 ; 10 \mathrm{nM}+187 \%, P<0.0001 ; 100 \mathrm{nM}$

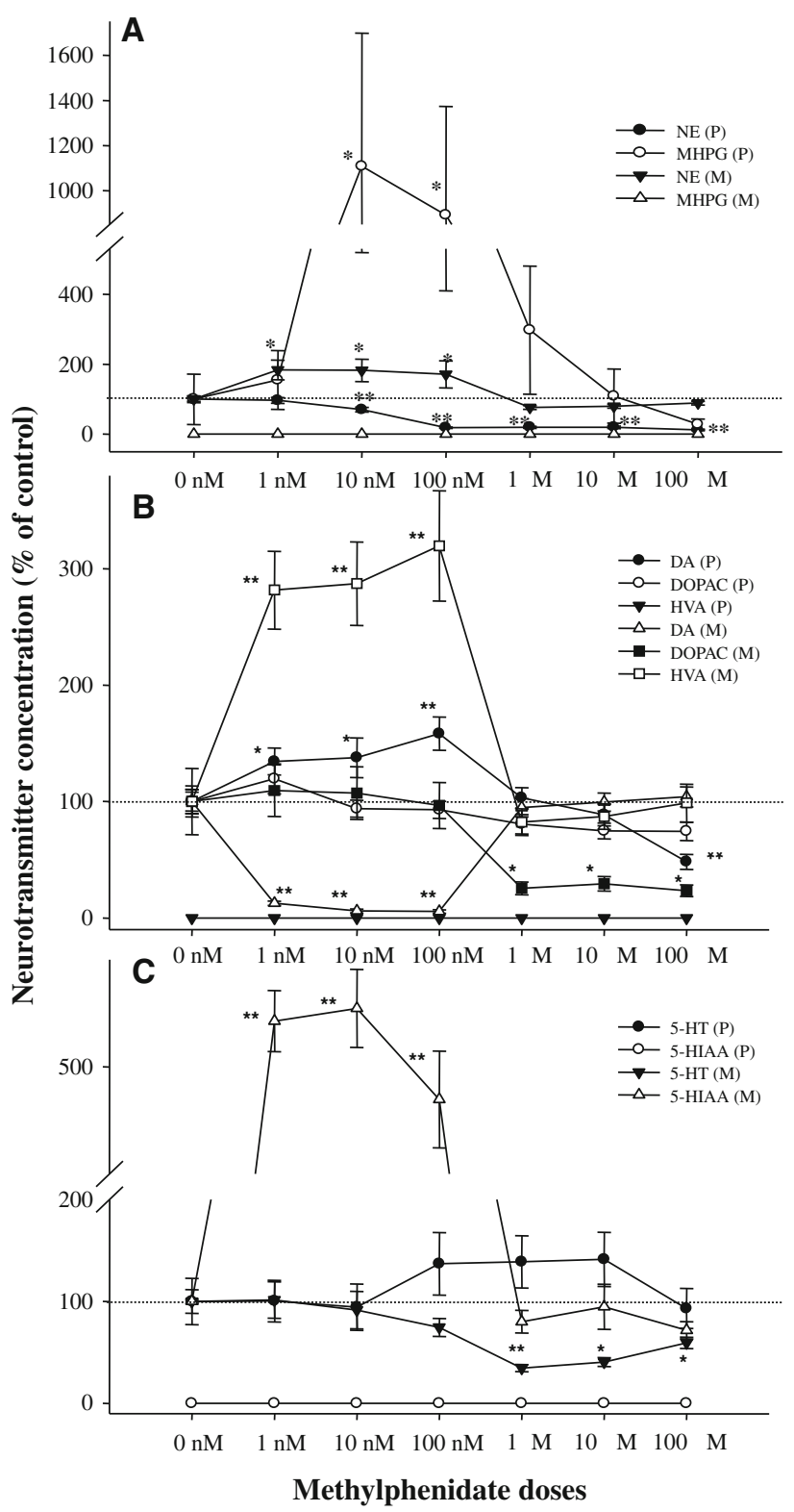

Fig. 1 Dose-dependent alteration of neurotransmitter levels in MPHtreated PC12 cells represented as a percent of the control $(\mathrm{MPH}=0 \mathrm{nM})$. a Norepinephrine $(N E)$ and its metabolite 3-methoxy-4-hydroxyphenylglycol $(M H P G)$, b dopamine $(D A)$ and its metabolites dihydroxyphenylacetic acid $(D O P A C)$ and homovanillic acid $(H V A)$, c serotonin $(5-H T)$ and its metabolite 5-hydroxyindole acetic acid (5-HIAA) were measured in pellets $(\mathrm{P}=$ intracellular) and the medium $(\mathrm{M}=$ extracellular). Independent experiments were conducted eight times, and HPLC measurements were done in duplicate $(n=8)$. $* * P<0.0001$ vs. MPH $=0 \mathrm{nM} ; * P<0.05$ vs. $\mathrm{MPH}=0 \mathrm{nM}$ using one-way ANOVA with post hoc Scheffe test. Error bars represent standard error in percent

$+220 \%, P<0.0001$ ), whereas treatment with high doses of MPH led to no relevant effect on the extracellular HVA concentration (Fig. 1b). An increased turnover of DA to HVA was observed at the lower doses of MPH (1-100 nM), whereas 
decreased turnover to DOPAC was observed at higher doses (Suppl. Table S1).

\section{Alteration of 5-HT and 5-HIAA levels}

The intracellular 5-HT concentration was $3-5 \mathrm{ng} / \mathrm{mL}$, but intracellular 5-HIAA was below the level of detection. The intracellular concentration of 5-HT and 5-HIAA was not significantly altered as a consequence of treatment with MPH at any dose (Fig. 1c).

The extracellular 5-HT concentration was $40-115 \mathrm{ng} / \mathrm{mL}$, and the extracellular 5-HIAA concentration was 14-107 $\mathrm{ng} / \mathrm{mL}$. The 5-HT concentration was significantly decreased after treatment with $1-100 \mu \mathrm{M} \mathrm{MPH}(1 \mu \mathrm{M},-65 \% ; 10 \mu \mathrm{M}$, $-60 \% ; 100 \mu \mathrm{M},-40 \%$ compared to control, $P<0.009)$, and the 5-HIAA concentration was significantly increased after treatment with lower doses of MPH $(1 \mathrm{nM}+430 \% ; 10 \mathrm{nM}$ $+440 \% ; 100 \mathrm{nM}+380 \%$ compared to control, $P<0.0001)$.
Extracellular 5-HT turnover to 5-HIAA was increased, especially at lower MPH doses (1-100 nM; Suppl. Table S1).

Localization of syt1, syt4, and stx1a in PC12 cells

The synaptic proteins syt 1 , syt 4 , and stx 1 a were detected in untreated PC12 cells via immunocytochemistry. Figure 2 shows the distribution and localization of the proteins with the neuronal vesicle protein syp (Fig. 2a, d, g) within the cells. Syt1 staining was located mainly in the soma (Fig. 2b). Similarly, syt4 expression was found in the cell body and punctuated in neurite-like processes (Fig. 2e). A high density of accumulated protein was perinuclear, possibly in the Golgi apparatus (Fig. 2f, arrow). The distribution pattern of syp and syt4 mostly correlated with one another. Stx 1a was spread in most areas of the PC12 cells (Fig. 2h). Stx 1a showed a similar distribution pattern as syp with a high level of coincidence (Fig. 2i). The cell's nucleus was unstained in all cases.
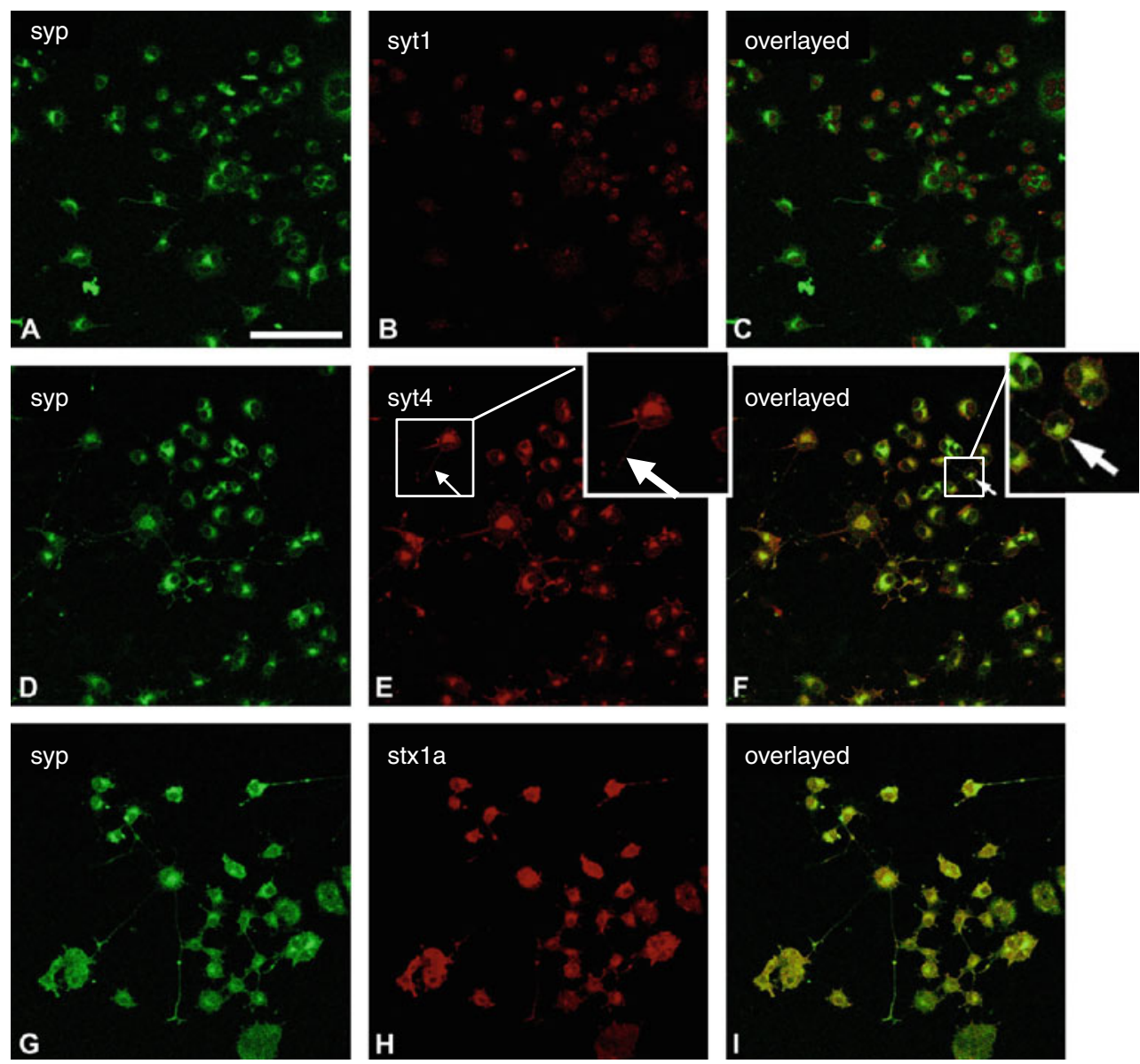

Fig. 2 Colocalization of synaptic proteins with synaptophysin (syp) on poly-D-lysine/laminin in PC12 cells. The immunolocalization of syp (a, $\mathbf{d}, \mathbf{g})$ revealed by a Cy2-coupled secondary antibody (green) was compared with syt1 (b), syt4 (e), and stx1a (h) immunostaining revealed by a Cy3-coupled secondary antibody (red) and superimposed (yellow; $\mathbf{c}, \mathbf{f}, \mathbf{i})$. The arrow indicates strong perinuclear syt 4 staining. Scale bar $100 \mu \mathrm{m}$ 
Gene expression profiles for synaptic proteins in MPH-treated PC12 cells

The influence of dose-dependent treatment with MPH on the expression of syt1, syt4, stx1a, and NET in the rat PC12 cell line was tested using QRT-PCR (Fig. 3). The expression of mRNA for all investigated genes was significantly reduced after treatment with $1 \mathrm{nM}$ MPH. Syt1 was downregulated $43 \% \quad(P<0.0001)$ compared to the control group. Additionally, the expression of syt4 $(-20 \%$, $P=0.04)$, stx1a $(-15 \%, P=0.045)$, and NET $(-27 \%$, $P=0.0014$ ) was down-regulated compared to the control. Higher doses of MPH did not show significant changes after ANOVA one-way post hoc Scheffe, but a significant down-regulation of NET after treatment with $10(-20 \%)$, $100 \mathrm{nM}(-26 \%)$, and with $10 \mu \mathrm{M}(-15 \%)$ was observed using a less conservative test (the student's t-test).

\section{Low doses of MPH enhance PC12 cell proliferation}

Because cell proliferation is associated with de novo DNA synthesis, we stained MPH-treated and untreated cells with BrdU to visualize its incorporation into DNA. A significantly larger population of PC12 cells displayed active DNA synthesis when treated with lower doses of MPH $(1,10,100 \mathrm{nM})$ compared to control $(+10-20 \%$ enhanced proliferation versus control, $P<0.05$; Fig. 4). Higher doses of MPH $(1,10,100 \mu \mathrm{M})$ had no effect on cell proliferation.

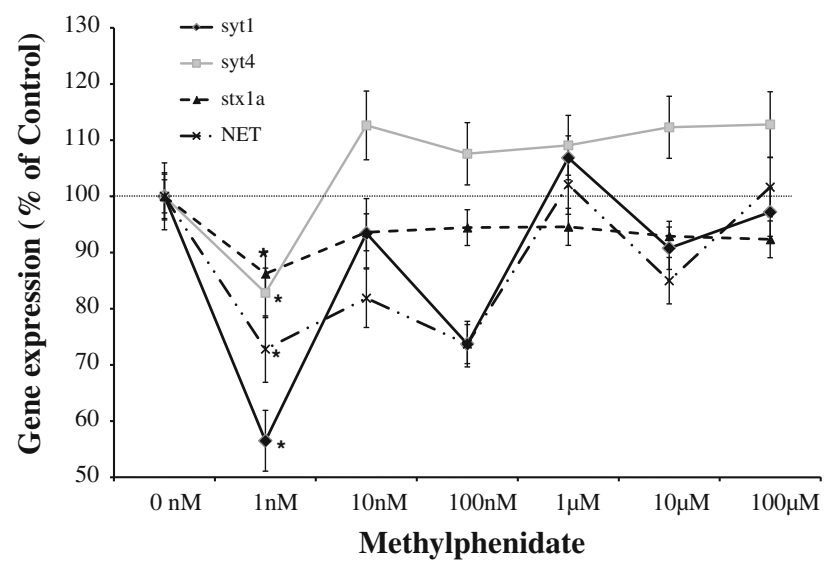

Fig. 3 Methylphenidate $(M P H)$ dose-dependent gene expression profiles in PC12 cells represented as the percent of control cells $(\mathrm{MPH}=0 \mathrm{nM})$. Gene expression was normalized to three housekeeping genes using the GeNorm method. Independent experiments were conducted twelve times, and QRT-PCR measurements were done in triplicate $(n=12)$. Syntaxin 1a stxla; synaptotagmin 1 syt1; synaptotagmin 4 syt4; norepinephrine transporter NET. $* P<0.05$ vs. $\mathrm{MPH}=0 \mathrm{nM}$ using one-way ANOVA with post hoc Scheffe test. Error bars represent standard error in percent

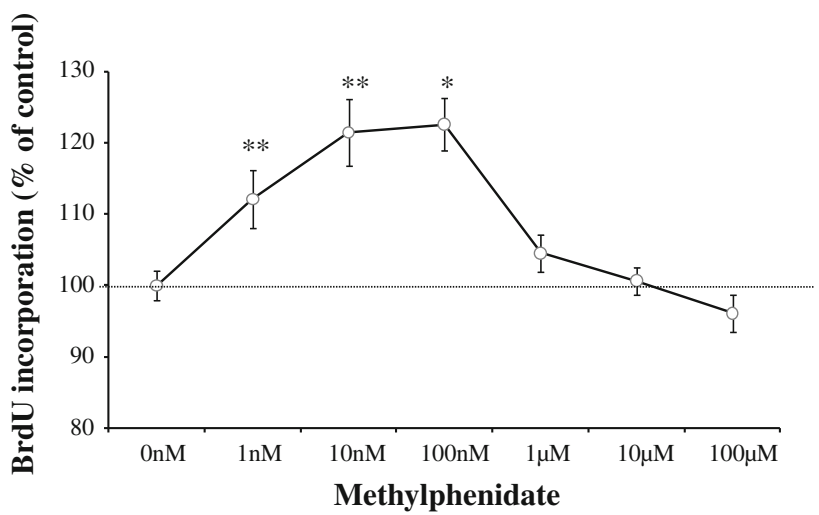

Fig. 4 Methylphenidate (MPH) dose-dependent effect on PC12 cell proliferation represented as the percent of control cells $(\mathrm{MPH}=0 \mathrm{nM})$. Independent experiments were conducted sixteen times, and BrdU incorporation was done in duplicate with four evaluated pictures for each dose $(n=16)$. The BrdU-positive cells were percental calculated to all stained cells $* * P<0.01, * P<0.05$ vs. MPH $=0 \mathrm{nM}$ using one-way ANOVA with post hoc Scheffe test. Error bars represent standard error in percent

\section{Discussion}

In this work, we presented the effects of low-dose MPH treatments after a short time at the level of extracellular and intracellular neurotransmitters and their metabolites, as well as its dose-dependent transcriptional effects on the expression of synaptic protein genes, excluding its inhibitory effects on the DAT (Suppl. Figure S1 and S2). A recent study used low doses of MPH (lowest dose $\sim 130 \mathrm{nM}$ ) to treat human neuroblastoma cell line to investigate the effect on cell survival (Schmidt et al. 2009). However, to the best of our knowledge, the present study is the first to deal with the impact of even lower doses of MPH. We showed that very low doses of MPH (1-100 nM) affect intra and extracellular neurotransmitter levels. The NE concentration was significantly higher (70-80\%) in the medium of treated PC12 cells compared to untreated cells, whereas the intracellular levels of NE were significantly lower after treatment with nanomolar concentrations of MPH. This outcome is generally consistent with the literature describing the interactions of this psychostimulant with biogenic amine transporter systems (Berridge, Devilbiss et al. 2006). MPH has been shown to inhibit NE uptake (Ferris, Tang et al. 1972; Wall, Gu et al. 1995) and bind to DAT and NET with high affinity, which leads to a higher extracellular monoaminergic level (Gatley, Pan et al. 1996; Volkow et al. 2002). Here, we report a novel finding; the intracellular DA concentration was significantly higher, whereas lower extracellular DA levels were detected after treatment with low doses of MPH. These results confirm with our additional finding that syt1 (one of our investigated synaptic protein) was also down-regulated after nanomolar treatment with MPH. Roden et al. (Roden, Papke et al. 2007) could show that after a stable RNA interference 
of syt 1 in PC12 cells, the DA release was $50 \%$ lower. They also found that NE release was lower, but because MPH is a potential NET blocker it seems that this effect is abrogated in our experiment with the PC12 lacking DAT (Suppl. Figure S1 and S2). MPH activation of the synthesizing enzyme, tyrosine hydroxyls, might also be one of the reasons to the increased DA levels, but this must be investigated for confirmation. Another potential reason for the higher intracellular DA level could be our findings regarding cell proliferation, although this must be interpreted cautiously since we would have expected than that all neurotransmitters would have increased at this dose treatment. Cell proliferation was enhanced significantly by $1-100 \mathrm{nM}$ of $\mathrm{MPH}$, whereas higher doses $(1-100 \mu \mathrm{M})$ caused no alteration. In contrast to (Lagace, Yee et al. 2006), who demonstrated an inhibition of neurogenesis in the juvenile rat brain after MPH administration, we could show higher proliferation rate in PC12 cells after low doses of MPH. Our present study as well as the other cell culture studies (Ludolph, Schaz et al. 2006) revealed mainly increased cell survival and proliferation after MPH treatment. However, one has to be cautious about constructing a link between in vitro cell culture results and in vivo mechanisms. In addition, we demonstrated that the change in extracellular DA metabolites DOPAC and HVA correlated with the breakdown of DA. After nanomolar MPH treatment, the extracellular DOPAC and HVA levels were higher compared to the intracellular level. The degradation of DA seems to be enhanced after MPH treatment; which might be through the activation of monoamine oxidase-B or catechol-O-methyltransferase activities via MPH. But such hypothesis should be further investigated.

The result obtained for the 5-HT metabolite 5-HIAA is an additional evidence for this potential hypothesis. In this case, we obtained also extracellularly the most significant results at nanomolar doses for 5-HIAA (5-HT metabolite). Interestingly, as soon as we raised the MPH doses to the micromolar range, the extracellular DA level was higher than the intracellular level, which is in accordance with previous reports showing that MPH increases the extracellular level of DA (Kuczenski and Segal 1997; Easton, Steward et al. 2007; Volz, Farnsworth et al. 2008).

We used much lower doses of MPH to demonstrate the potency of MPH at lower doses than what was expected until now. Using a cell line model, we must take into account that doses used in vitro should be conferred to an in vivo model; therefore, an adaptation of the drug doses from the micromolar range to the nanomolar range has to be assumed. We showed that low doses of MPH not only alter neurotransmitter release, but also influence synaptic gene expression. We investigated the expression of NET and synaptic protein genes, including syt1, syt4, and stx $1 \mathrm{a}$, which is a part of the soluble $N$-ethylmaleimide-sensitive factor attachment receptor (SNARE) core complex.
SNARE proteins assemble into a very stable $\alpha$-helical complex between two membranes. The formation of the SNARE complex brings two membranes closer and thus leads to membrane fusion. A previous study (Sung and Blakely 2007) demonstrated a direct interaction between NET and stx1a, a protein involved in vesicle trafficking and docking. Importantly, the NET/stx1a interaction appears to be not irrevocable, but rather can be modulated rapidly by extracellular stimuli such as a psychostimulant. Stxla regulates NET through two mechanisms, one involving the delivery of NET to the plasma membrane and a second involving the inactivation of its catalytic function. How these mechanisms are linked to neuronal activation or second messenger responses remains to be elucidated. Our results show that stx1a mRNA decreases after all MPH doses, but a significant effect was observed only with $1 \mathrm{nM}$ MPH. Interestingly, all investigated synaptic proteins and NET are down-regulated at this low concentration. The significant down-regulation of synaptic proteins by $1 \mathrm{nM}$ MPH shows a strong link to the extracellular DA level. We measured a much lower DA level in the medium after treatment with $1 \mathrm{nM}$ MPH compared to untreated cells (Fig. 1b). Synaptic protein expression can be regulated by the dopamine receptor pathway. DA can activate extracellular signal-regulated kinase (ERK) signaling by stimulating both the D1- and the D2-family receptors. Zachor and colleagues demonstrated for the first time that wildtype PC12 cells express D1 and D2 receptor proteins (Zachor, Moore et al. 2000). Activated ERK induces cAMP response element-binding protein (CREB) phosphorylation and c-fos expression, which further regulate target gene expression, including synaptic proteins. Changes in the expression of these genes may contribute to different aspects of long-term neuro-adaptation (Zhang and $\mathrm{Xu}$ 2006). The consequence of low levels of DA is a decreased expression of synaptic proteins. Comparing the gene expression profiles of syt 1 and NET after treatment with $\mathrm{MPH}$, they have almost the same progression, which might indicate a common mechanism of action. This theory must be further investigated.

Summarizing our results, we showed that much lower MPH doses than expected are biologically active and lead to an alteration of neurotransmitter release, neurotransmitter metabolism, cell proliferation, and the expression of certain genes. Additional investigations into intermediate nanomolar doses of MPH are necessary for further confirmation.

Acknowledgments The authors express their appreciation for the funding that was provided by the "Deutsche Forschungsgemeinschaft (DFG)" in the "Klinische Forschergruppe Aufmerksamkeitsdefizit-/ Hyperaktivitätssyndrom (ADHS)" KFO-125 http://www.uni-wuerzburg. de/nervenklinik/psychobiologie/kfg/index.html. We would like to thank Dr. Silvia Mandel for the generous gift of the PC12 cells. We would also 
like to add a special thanks to Mrs. Gabriela Ortega, Ms Miryame Hofmann and Mr. Rainer Burger for their excellent technical work and help. Funding for this study was provided by "Deutsche Forschungsgemeinschaft (DFG)" Grant KFO-125; the DFG had no further role in study design; in the collection, analysis, and interpretation of data; in the writing of the report; and in the decision to submit the paper for publication.

Conflict of interest All other authors declare that they have no conflicts of interest.

\section{References}

Berridge CW, Devilbiss DM et al (2006) Methylphenidate preferentially increases catecholamine neurotransmission within the prefrontal cortex at low doses that enhance cognitive function. Biol Psychiatry 60(10):1111-1120

Biederman J, Faraone SV (2005) Attention-deficit hyperactivity disorder. Lancet 366(9481):237-248

Easton N, Steward C et al (2007) Effects of amphetamine isomers, methylphenidate and atomoxetine on synaptosomal and synaptic vesicle accumulation and release of dopamine and noradrenaline in vitro in the rat brain. Neuropharmacology 52(2):405-414

Ferris RM, Tang FL et al (1972) A comparison of the capacities of isomers of amphetamine, deoxypipradrol and methylphenidate to inhibit the uptake of tritiated catecholamines into rat cerebral cortex slices, synaptosomal preparations of rat cerebral cortex, hypothalamus and striatum and into adrenergic nerves of rabbit aorta. J Pharmacol Exp Ther 181(3):407-416

Gatley SJ, Pan D et al (1996) Affinities of methylphenidate derivatives for dopamine, norepinephrine and serotonin transporters. Life Sci 58(12):231-239

Hahn MK, Steele A et al (2009) Novel and functional norepinephrine transporter protein variants identified in attention-deficit hyperactivity disorder. Neuropharmacology 57(7-8):694-701

Han DD, Gu HH (2006) Comparison of the monoamine transporters from human and mouse in their sensitivities to psychostimulant drugs. BMC Pharmacol 6:6

Jaeger CB (1985) Immunocytochemical study of PC12 cells grafted to the brain of immature rats. Exp Brain Res 59(3):615-624

Kadota T, Yamaai T et al (1996) Expression of dopamine transporter at the tips of growing neurites of $\mathrm{PC} 12$ cells. J Histochem Cytochem 44(9):989-996

Kim CH, Hahn MK et al (2006) A polymorphism in the norepinephrine transporter gene alters promoter activity and is associated with attention-deficit hyperactivity disorder. Proc Natl Acad Sci USA 103(50):19164-19169

Kuczenski R, Segal DS (1997) Effects of methylphenidate on extracellular dopamine, serotonin, and norepinephrine: comparison with amphetamine. J Neurochem 68(5):2032-2037

Lagace DC, Yee JK et al (2006) Juvenile administration of methylphenidate attenuates adult hippocampal neurogenesis. Biol Psychiatry 60(10):1121-1130

Ludolph AG, Schaz U et al (2006) Methylphenidate exerts no neurotoxic, but neuroprotective effects in vitro. J Neural Transm 113(12): 1927-1934

Riederer P, Reynolds GP (1981) Determination of a wide range of urinary amine metabolites using a simple high-performance liquid chromatographic technique. J Chromatogr 225(1):179-184

Roden WH, Papke JB et al (2007) Stable RNA interference of synaptotagmin I in PC12 cells results in differential regulation of transmitter release. Am J Physiol Cell Physiol 293(6):C1742-C1752

Schmidt A, Krieg J et al. (2009) Impact of drugs approved for treating ADHD on the cell survival and energy metabolism: an in vitro study in human neuronal and immune cells. J Psychopharmacol. doi: $10.1177 / 0269881109105563$

Shafer TJ, Atchison WD (1991) Transmitter, ion channel and receptor properties of pheochromocytoma (PC12) cells: a model for neurotoxicological studies. Neurotoxicology 12(3):473-492

Sung U, Blakely RD (2007) Calcium-dependent interactions of the human norepinephrine transporter with syntaxin 1A. Mol Cell Neurosci 34(2):251-260

Vandesompele J, De Preter K et al. (2002) Accurate normalization of realtime quantitative RT-PCR data by geometric averaging of multiple internal control genes. Genome Biol 3(7):RESEARCH0034

Volkow ND, Fowler JS et al. (2002) Mechanism of action of methylphenidate: insights from PET imaging studies. J Atten Disord 6(Suppl 1):S31-S43

Volz TJ, Farnsworth SJ et al (2008) Methylphenidate-induced alterations in synaptic vesicle trafficking and activity. Ann N Y Acad Sci 1139:285-290

Wall SC, Gu H et al (1995) Biogenic amine flux mediated by cloned transporters stably expressed in cultured cell lines: amphetamine specificity for inhibition and efflux. Mol Pharmacol 47(3):544-550

Wilens TE (2008) Effects of methylphenidate on the catecholaminergic system in attention-deficit/hyperactivity disorder. J Clin Psychopharmacol 28(3 Suppl 2):S46-S53

Zachor DA, Moore JF et al (2000) Cocaine inhibits NGF-induced PC12 cells differentiation through $\mathrm{D}(1)$-type dopamine receptors. Brain Res 869(1-2):85-97

Zhang J, Xu M (2006) Opposite regulation of cocaine-induced intracellular signaling and gene expression by dopamine D1 and D3 receptors. Ann N Y Acad Sci 1074:1-12 